\author{
P. L. Nimis, S. Martellos \& E. Pittao
}

\title{
Ecology and functional traits of lichens in the archaeological areas of Latium
}

\author{
Nimis, P. L., Martellos, S. \& Pittao, E.: Ecology and functional traits of lichens in the archaeo- \\ logical areas of Latium. — Bocc. 28: 181. 2019. - ISSN: 1120-4060 printed, 2280-3882 \\ online. \\ Key words: ITALIC, morpho-biological traits, management.
}

A matrix of the 263 species of saxicolous lichens known to occur in the archaeological areas of Latium and ecological data plus morpho-biological traits, retrieved from ITALIC (the Information System of Italian Lichens), was submitted to multivariate analysis (classification and ordination). The species are ordered along a complex gradient whose main drivers are increasing aridity (paralleled by increasing light intensity) and $\mathrm{pH}$ of the substrates. The occurrence of endolithic lichens (mainly on limestone) and of sorediate lichens (mainly in shaded and/or eutrophicated situations) requires special attention whenever their removal is attempted. The use of biocides in the presence of endolithic lichens may cause irreversible damage to the rock surfaces, while mechanical removal of sorediate lichens may increase their further spreading. Heat shock treatments may prove to be the most effective and less harmful strategy for the removal of lichens from monuments, but their growth rates should be always taken into consideration when attempting such measures, which often prove to be ineffective within short time-spans. However, the high lichen diversity of archaeological areas, mainly due to the presence of widely different allochtonous substrata, should be considered as a value in itself. Removal of the lichens should be attempted only when strictly necessary, and their diversity should be highlighted as an added value to the cultural interest of archaeological sites.

Address of the authors:

Pieluigi Nimis, Stefano Martellos \& Elena Pittao,

Department of Life Sciences, University of Trieste, Trieste, Italy. E-mail: nimis@units.it 
